\title{
TRADISI LISAN DAN IDENTITAS BANGSA; STUDI KASUS KAMPUNG ADAT SINARRESMI, SUKABUMI
}

\author{
Oral literature and National Identyty: The Case Study of Indigenous \\ Village Sinar Resmi, Sukabumi
}

Oleh Yeni Mulyani Supriatin

Balai Bahasa Provinsi Jawa Barat

Email: yeni.mulyani@yahoo.com

\begin{abstract}
Abstrak
Tradisi lisan adalah warisan leluhur yang banyak menyimpan kearifan lokal, kebijakan, dan filosofi hidup yang terekspresikan dalam bentuk mantera, pepatah-petitih, pertunjukan, dan upacara adat. Tradsi lisan, yang terdapat di Nusantara, sekaligus juga menyimpan identitas bangsa karena pada tradisi lisan terletak akar budaya dan akar tradisi sebagai subkultur atau kultur Indonesia. Beberapa isu penting yang menghadang Indonesia saat ini, yakni kemiskinan, ketimpangan sosial, identitas, dan nasionalisme. Salah satu upaya penguatan identitas dan ideologi nasionalisme adalah dengan jalan memberikan perhatian yang lebih pada pembangunan dan pengembangan budaya. Dalam kaitan itu, makalah ini mengangkat kasus kampung adat di Sinarresmi, Sukabumi, yang memperlihatkan bagaimana komunitas adat di kampung tersebut mampu memenuhi kebutuhan hidup sehari-hari dari sumber daya alam yang ada di kampung tersebut. Mereka mengelola alam tanpa merusak alam, secara ekonomi bisa menafkahi diri mereka dari alam di lingkungan tersebut dengan pranata sosial yang berjalan harmonis.Penelitian ini menerapkan teori yang berkaitan dengan tradisi lisan yang dikemukakan, antara lain oleh Walter J. Ong, Vansina, dan Ikram, sedangkan metode yang digunakan adalah metode modern yang dipaparkan oleh Danandjaja.
\end{abstract}

Kata kunci: tradisi lisan, identitas bangsa, dan Kampung Adat Sinarresmi.

\begin{abstract}
Oral tradition is the heritage of the many stores local knowledge, wisdom, and philosophy of life is expressed in the form of incantations, proverbs-proverb, performances and ceremonies. Oral tradition, contained in the archipelago, as well as keep the identity of the nation because the oral tradition is cultural roots and the roots of the tradition as a subculture or culture of Indonesia. Some of the important issues facing Indonesia today, namely poverty, social inequality, identity, and nationalism. One of the efforts to strengthen the identity and ideology of nationalism is by giving more attention to the construction and development of culture. In that regard, this paper raised the case of indigenous villages in Sinarresmi, Sukabumi, which shows how the indigenous communities in the village is able to meet the daily living needs of the natural resources
\end{abstract}


that exist in the village. They manage nature without destroying nature, can economically provide for themselves from the natural environment with a harmonious social order. This study applies the theory of oral traditions relating to the proposed, among others, by Walter J. Ong, Vansina, and Ikram, while the methods used are modern methods presented by Danandjaja.

Keywords: oral traditions, national identity, and Villages Customs Sinarresmi.

\section{A. PENDAHULUAN}

Suatu keniscayaan yang tidak dimungkiri bahwa tradisi lisan merupakan cultural heritage yang mengandung berbagai kearifan lokal, nilai-nilai budaya, dan kebijakan yang terekspresikan dalam cerita rakyat, seni pertunjukan rakyat, dan berbagai ritual dalam upacara adat. Cultural heritage atau warisan budaya ini merupakan kekayaan bangsa Indonesia yang harus kita pelihara dan kita lestarikan karena di dalamnya menyimpan identitas budaya sekaligus sebagai akar budaya yang merupakan subkultur atau kultur Indonesia, sebagaimana dinyatakan oleh Pudentia (17 Oktober 2012) bahwa tradisi lisan bukanlah kekayaan budaya semata melainkan sebagai identitas bangsa yang bernilai dan sulit ditakar. Oleh karena itu, pemahaman akan tradisi lisan tidak hanya berkisar pemberian suatu ruang agar tradisi tersebut bisa digelar, tetapi secara tekstual dan kontekstual, tradisi lisan tersebut juga harus dipahami. Tujuannya adalah agar nilai yang melekat dalam tradisi lisan tersebut bisa dipahami oleh masyarakat pada era modern.

Hal itu perlu ditegaskan dengan asumsi bahwa pada saat ini masyarakat Indonesia modern berada pada posisi "buta" terhadap nilai-nilai asli mereka, yang melupakan bahwa mereka tidak melestarikan nilai-nilai asli mereka, yang melupakan masa lalu, melupakan asalmula, dan seperti orang hilang ingatan yang mengabaikan sejarah mereka. Akibatnya, mereka terasingkan dan teralienasi dari budaya-budaya asal. Gagalnya kebijakan pendidikan dan pembangunan di Indonesia bagi Sumardjo (2003) disebabkan, antara lain, oleh "kebutaan" terhadap budaya asli Indonesia dan kurangnya perhatian pemerintah terhadap pengembangan budaya. Oleh karena itu, dipandang penting menggali, mengingat, dan menghidupkan kembali nilai-nilai etnis yang asli, yang terdapat dalam tradisi lisan.

Sebagaimana telah dikemukakan di dalam abstrak bahwa pembangunan yang dilakukan untuk mengatasi berbagai persoalan bangsa yang hanya menyandarkan pada pertumbuhan ekonomi yang didominasi dengan perusahaan multinasional menyebabkan pudarnya masalah identitas dan rasa nasionalisme. Dengan demikian, salah satu upaya penguatan identitas bangsa dan rasa nasionalisme adalah memberikan perhatian yang lebih pada pembangunan dan pengembangan budaya, sebagaimana dinyatakan oleh Sumardjo (2003) bahwa kita tidak dapat membangun masa depan tanpa mempertimbangkan akar tradisi karena akar itulah kekuatan kita. Hidup tanpa akar niscaya lama-lama tumbang.

Makalah ini akan mengungkapkan tradisi lisan dan identitas bangsa dalam studi kasus yang terjadi di Kampung Adat Sinar Resmi, Desa Sinar Resmi, Cisolok, Kabupaten Sukabumi. Masyarakat adat Sinar Resmi dalam menata kehidupan sehari-hari atau dalam membangun struktur ekonomi yang diperuntukkan kemaslahatan komunitas pendukungnya menyandarkan pada tradisi leluhur mereka yang senantiasa dijaga dan dilestarikan. Tradisi lisan yang terdapat di Kampung Adat Sinar Resmi yang terekspresikan dalam seni pertunjukan adalah Gondang Buhun dan Dogdog Lojor serta berbagai upacara ritual yang berkaitan dengan penanaman padi.

Kamus Besar Bahasa Indonesia (KBBI:1999) mencantumkan kata tradisi 
dalam dua makna, yakni (1) adat kebiasaan turun-temurun dari nenek moyang yang masih dijalankan dalam masyarakat dan (2) penilaian atau anggapan bahwa caracara yang telah ada merupakan cara yang paling baik dan benar. Meskipun terasa umum, makna kata tradisi dalam KBBI masih dapat diterima terutama dalam makna (1) yang menyatakan turun-temurun dan dalam makna (2) yang menyatakan bahwa di dalam tradisi mengandung kebaikan dan kebenaran meskipun baik dan benar di sini bersifat lokalitas, misalnya dalam tradisi yang terungkap di Kasepuhan Sinar Resmi terdapat pandangan yang menyatakan bahwa dalam proses regenerasi atau suksesi kepemimpinan, seorang pemimpin kasepuhan harus mewariskan kepemimpinan pada anak lelaki. Jika dalam kasepuhan memiliki anak lelaki lebih dari satu orang, pewarisannya didasarkan pada wangsit yang diterima pemimpin kasepuhan. Jadi, putra lelaki pertama belum tentu mewarisi pemimpin kasepuhan. Kemudian, jika tidak memiliki anak lelaki, pemimpin kasepuhan dibenarkan memiliki istri lebih dari satu orang sampai kasepuhan memperoleh putra mahkota sebagai ahli waris.Tindakan yang dilakukan pemimpin kasepuhan mengambil istri lebih dari satu orang dalam relevansinya dengan mencari turunan anak lelaki sebagai pewaris kasepuhan, di mata masyarakat Kasepuhan Sinar Resmi merupakan tindakan terbaik dan terpuji. Di sisi lain, makna (2) dari KBBI tersebut minimal dapat menepis mitos yang sudah beredar dalam masyarakat bahwa tradisi senantiasa dimaknai sebagai segala sesuatu yang berasal dari masa lampau. Padahal, realitasnya tidaklah demikian, sebagaimana dinyatakan oleh Baso (2003) bahwa tradisi tidak hadir sebagaimana adanya pada masa lalu, tetapi pasti telah mengalami proses seleksi atau bongkar ulang sehingga ada yang dipopulerkan atau dipinggirkan bergantung pada relasi kekuasaan yang bermain di sekitarnya.
Sementara itu, frasa tradisi lisan dapat dipahami sebagai tradisi yang berkorelasi pada fase situasi masyarakat yang belum mengenal tradisi tulis-menulis, sebagai salah satu bentuk komunikasi, sebagai medium transformasi nilai, norma, dan hukum yang pewarisannya berlangsung dari satu individu ke individu atau dari satu generasi ke generasi, sebagaimana dalam pandangan Vansina (1985) yang mengatakan bahwa tradisi lisan adalah pesan verbal atau tuturan yang disampaikan dari generasi ke generasi secara lisan, diucapkan, dinyanyikan, dan disampaikan dapat dengan menggunakan alat musik dalam suatu pertunjukan yang di dalamnya mengandung transmisi verbal dan nonverbal. Pernyataan Vansina tersebut sesungguhnya dapat diterima jika pewarisan tradisi lisan (yang merupakan pengetahuan) dari "satu bentuk kekuasaan tertentu", baik secara esoteris maupun secara eksoteris berlaku dalam suatu kelompok kolektif. Hal ini mengimplikasikan bahwa dalam proses regenerasi selalu ada penyematan unsur atau motif kepentingan.

James Danandjaja pada tahun 1972 mulai melakukan kajian mendalam tentang tradisi lisan (yang ia istilahkan dengan folklor) Indonesia. Danandjaja mendefinisikan folklor sebagai berikut.

"...sebagian dari kebudayaan yang tersebar dan diwariskan turun-temurun secara tradisional, di antara anggotaanggota kolektif apa saja di Indonesia, dalam versi yang berbeda-beda, baik dalam bentuk lisan maupun dalam bentuk contoh yang disertai dengan perbuatan-perbuatan dan alat-alat bantu pengingat, mnemonic devices (Danandjaja, 1991:460) .

Apabila memerhatikan pendapat Ong (Mulyani, 2012)) kelisanan itu sesungguhnya mengalami tahapan-tahapan tertentu sesuai dengan zamannya. Menurut Ong, bahasa pada hakikatnya bersifat lisani (oral). Begitu lisannya sehingga seakan-akan aksara tidak diperlukan. Ong membuktikan pernyataannya dengan menyebutkan bahwa di antara puluhan ribu 
bahasa yang digunakan di dunia hanya seratus enam yang memiliki sistem tulisan, sebagian besar hidup dalam keniraksaraan yang menurut Ikram (2008: 205) bahwa semua fungsi tulisan nyaris tidak dimanfaatkan meskipun kiat tulis-baca dikuasai atau pernah dikuasai.

Pernyataan Ong merefleksikan bahwa bentuk kelisanan memiliki tahapan sesuai dengan perkembangan peradaban. Dan, dalam bukunya yang terkenal Orality and Literacy: The Technologizing of the Word, Ong memperlihatkan tahapantahapan perkembangan kebudayaan kelisanan mulai dari kelisanan tahap awal, era tulisan, masa mesin cetak mengubah peradaban, dan masa ketika media elektronik mulai berperan, ketika manusia memasuki masa kelisanan tahap kedua.

Perkembangan kebudayaan kelisanan tersebut tercakup dalam dua bentuk kelisanan, yakni kelisanan primer dan kelisanan sekunder yang ditegaskan oleh Ong (1982:11) bahwa keduanya berbeda. Kelisanan primer mengacu pada pemikiran kelisanan suatu kebudayaan yang sama sekali tidak tersentuh oleh pengetahuan tentang tulis-menulis dan cetak-mencetak. Dengan kata lain, kelisanan primer atau disebut juga kelisanan dasar untuk kebudayaan yang sama sekali tidak pernah mengenal tulisan. Ikram (2008:205) menjelaskan bahwa kelisanan primer adalah kelisanan yang mengimplikasikan bunyi, memiliki kekhasan bahwa begitu ia ada, begitu pula tiada; sifatnya sesaat, tidak lestari, dan tidak dapat dihentikan. Justru sifatnya yang demikian itu pada bangsa-bangsa tertentu memberi kekuatan magis pada mantra yang harus dihafal tanpa salah supaya efektif. Tidak ada dukun yang melafalkan mantra dengan membacanya dari buku atau tulisan. Dapat dipastikan bahwa pada zaman keniraksaraan timbul keperluan untuk mengingat kembali apa yang telah dilisankan terlebih jika itu berupa petuah yang ingin ditransmisikan pada generasi berikutnya. Daya ingat menjadi sangat penting serta sangat dihargai dan diusahakan. Sejalan dengan itu, Lord dan Sweeney (2008:205) menemukan formula sebagai peranti mnemonik yang membantu orang menemukan kembali pikiran yang tersimpan dalam ingatan. Ong (1982:34) merumuskan usaha mengingat sebagai think memorable thoughts (agar mudah diingat).

Seiring perkembangan zaman, ketika manusia mengenal budaya tulis yang di Indonesia dikenal pada abad ke-5 sebagaimana dinyatakan oleh Dienaputra dan Ekadjati dalam (Sabana. Ed, 2005:20, 55) informasi dan pengetahuan yang bersifat lisan dituangkan dalam catatancatatan agar tidak musnah ditelan zaman. Meskipun sudah menjadi manuskrip karena masih dapat dilantunkan, dituturkan, dipentaskan, ditransmisikan, dan dilisankan, dapat digolongkan ke dalam tradisi lisan. Ong (1982:11) menyebut hal itu sebagai tahap orality residu atau 'residu kelisanan'. Residu menjadi penanda awal kelisanan sekunder. Pudentia (2008:384) mengilustrasikan situasi kelisanan sekunder pada abad modern ini jauh berbeda, baik dengan kelisanan primer maupun dengan kelisanan residu. Saat ini berkembangnya teknologi informasi yang luar biasa cepat, pementasan tradisi suka atau tidak suka, dengan sendirinya masuk dalam bisnis industri media. Kekuatan industri media amat mewarnai wajah tradisi lisan masa kini. Ong (1982:136) menyebutkannya sebagai secondary orality yang menjelaskan bahwa kita sudah masuk dalam kelisanan tahap kedua. Tradisi lisan tidak lagi tampil ketika penutur bertemu langsung dengan penonton/penikmatnya dalam ruang waktu dan tempat yang sama, tetapi muncul dalam kemasan rekaman video atau kaset yang dapat dihadirkan kapanpun.

Situasi secondary orality menurut Pudentia menuntut penikmat atau peneliti tidak harus mempersoalkan mana versi tradisi asli atau yang lengkap. Kehadiran tradisi lisan sebaiknya diterima apa adanya sesuai dengan konsep, prinsip, dan alasan peneliti untuk dipertanggungjawabkan 
secara akademis. Yang menarik adalah melihat kelenturan yang menjadi penanda tradisi lisan dalam pementasannya. Fleksibilitas tradisi lisan merupakan keniscayaan sejauh para penutur dan komunitas pemiliknya menghendaki atau menerimanya.

Sudah dapat dipastikan bahwa pendekatan yang digunakan untuk menelaah tradisi lisan pada tiap-tiap penelitian berbeda. Dalam hal ini diperlukan syarat-syarat khusus untuk memasuki ruang ini, utamanya pemahaman mengenai logika pengetahuan lokal yang memadai. Hal ini sangat penting mengingat kedudukan peneliti biasanya berangkat dari kerangka formal yang telah dibingkai oleh institusi pendidikan bergaya barat, sedangkan tradisi Timur sejak awal diketahui memiliki kekhahasan terutama sistem kosmologinya. Namun, tidak berarti kehilangan benang merah yang dapat menjadi kerangka acuan saat memandang tradisi lisan. Yang perlu ditegaskan adalah tradisi lisan berarti juga tindak tutur yang merupakan sebuah pernyataan sikap dan bersifat ideologis.

Penelitian ini akan menggunakan pendekatan modern yang dikemukakan oleh Danandjaja (Ed. Pudentia), 2008:61. Danandjaja mengatakan bahwa pendekatan modern memerhatikan aspek folk dan lore dari tradisi lisan yang dikaji. Sebagaimana diketahui bahwa folk adalah sekelompok orang yang memiliki ciri-ciri pengenal fisik, sosial, dan kebudayaan sehingga dapat dibedakan dari kelompok-kelompok lain, sedangkan yang dimaksudkan dengan lore adalah tradisi folk, sebagian kebudayaannya yang diwariskan turunmenurun secara lisan atau melalui suatu contoh yang disertai gerak isyarat atau alat bantu pengingat. Dengan demikian, pendekatan modern lebih bersifat holistik, artinya ketika mengkaji tradisi lisan, peneliti akan mengaitkan tradisi lisan tersebut dengan latar belakang atau konteks kebudayaan tradisi lisan tersebut sehingga hasil kajiannya bersifat emik, yaitu mempertimbangkan aspek folk yang menjadi objek kajian tradisi lisan. Berbeda dengan dua pendekatan lainnya yang juga digunakan untuk mendekati tradisi lisan, yaitu pendekatan humanistis dan antropologis. Pendekatan humanistis meniitikeratkan pada aspek lore daripada folk, sedangkan pendekatan antropologis lebih memfokuskan pada aspek folk daripada lore ketika mengkaji tradisi lisan.

Selanjutnya, untuk mendukung pendekatan modern tersebut, dalam tahap pengumpulan data diterapkan teknik pendokumentasian, perekaman, dan pewawancaraan terhadap folk dan lore yang menjadi objek kajian sebagai bahan analisis yang menginterpretasi kaitan antara folk dan lore. Di sisi lain, untuk pengecekan keabsahan data akan dilakukan pula dua teknik, yaitu:

(1) Ketekunan pengamatan. Teknik ini bertujuan untuk menemukan ciri-ciri dan unsur-unsur dalam situasi yang sangat relevan dengan persoalan atau isu yang sedang dicari. Dalam hal ini peneliti dituntut untuk lebih teliti, rinci, dan berkesinambungan ketika melakukan pengamatan terhadap faktor-faktor yang menonjol. Oleh karena itu, dalam teknik ini peneliti harus mampu menentukan penutur yang layak menjadi sumber data, kemudian menguraikan secara rinci bagaimana faktor yang ditelaah dapat dipahami.

(2) Triangulasi, teknik ini digunakan untuk memeriksa keabsahan data dengan memanfaatkan sesuatu yang lain di luar data untuk keperluan pengecekan atau sebagai pembanding terhadap data itu. Dalam penelitian ini triangulasi dilakukan dalam mengecek, baik suatu informasi maupun suatu data yang terdapat dalam sumber data dengan metode yang sama dengan waktu yang berbeda.

\section{B. HASIL DAN BAHASAN}

1. Kasepuhan Sinar Resmi Selayang
Pandang 
Tradisi lisan yang terdapat di Kabupaten Sukabumi dilestarikan oleh lingkungan masyarakat adat, yaitu Kasepuhan Cipta Gelar, Sinar Resmi, Sinar Rasa, dan Cipta Mulya. Keempat kasepuhan itu berasal dari turunan yang sama, yaitu masyarakat adat Banten Kidul 'Selatan'. Dengan demikian, masyarakat adat di Kabupaten Sukabumi adalah komunitas adat dengan segala kearifan lokalnya yang dalam kesehariannya menjalankan sosio-budaya tradisional yang mengacu pada karakteristik budaya Sunda pada abad ke-18. Komunitas ini hidup secara turun-temurun dari generasi ke generasi dengan tradisi yang dipelihara dan diperkuat sebagai perwujudan rasa syukur dan penghormatan pada leluhur yang lahir dari sebuah proses sejarah yang tidak terputus dalam perjalanan masa untuk terus menegakkan martabat dan hak asal-usul sebagai identitas budaya dan warisan budaya nasional. Dengan sistem yang diwariskan para leluhur, masyarakat adat di Kabupaten Sukabumi menata seluruh kehidupannya, baik sebagai individu maupun sebagai kelompok sosial dan religius yang khas yang berbeda dengan masyarakat biasa di sekitarnya. Sistemsistem inilah yang dipertahankan dan diperjuangkan sebagai sumber semangat hidup yang terkandung dalam sistem adat yang masih dibudayakan dan dilestarikan.

Yang menjadi objek penelitian ini adalah tradisi lisan yang dilestarikan dalam masyarakat adat Kasepuhan Sinar Resmi. Kasepuhan Sinar Resmi terletak di kawasan kaki Gunung Halimun-Salak, berada di Desa Sirna Resmi, Kecamatan Cisolok, Kabupaten Sukabumi. Jarak desa $23 \mathrm{~km}$ dari kecamatan dan $33 \mathrm{~km}$ dari kabupaten. Akses lalu-lintas menuju desa ini "cukup mudah" dalam arti kondisi jalan yang relatif licin sehingga dalam waktu dua jam dari Pelabuhan Ratu sudah tiba di Desa Sirna Resmi. Memasuki lokasi kasepuhan, dari ketinggian tampak deretan rumah panggung, berdinding bilik bambu, dan beratap rumbia. Rumah masyarakat kasepuhan terbuat dari material alam dan strukturnya mengikuti hukum alam. Abah Asep Nugraha menjelaskan bahwa model perumahan kasepuhan beratap ijuk atau tepus yang merupakan bahan baku lokal yang tersedia di alam sejak ada kehidupan manusia. Di samping itu, budaya juga mengajarkan masyarakat kasepuhan untuk menggunakan bahan yang tersedia di alam. Secara budaya, adat kasepuhan terbiasa dengan rumah panggung, bambu, atau pohon kelapa. Selain tahan gempa dan nyaman, rumah panggung penuh makna. Menurut adat Kasepuhan Banten Kidul, rumah panggung terdiri atas 3 bagian, yakni kolong, beuteung 'tengah', dan para 'atas'. Kolong menurut Abah adalah simbol alam raya, tempat manusia, beuteung simbol manusia yang mewariskan budaya dan bersyukur, serta para simbol tempat para penguasa alam raya.

Imah gede 'rumah pemimpin adat' menggambarkan penataan ruang yang terdiri atas taweran 'teras', sema 'ruang tamu', ruang baris olot 'orang yang dituakan yang mempunyai kedudukan di kasepuhan', ruang dapur, dan ruang pemimpin kasepuhan tempat Abah menerima tamu, menyimpan perbendaharan pusaka dan kasur leutik 'kecil'/kursi takhta. Seluruh ruangan tidak menampakkan kursi.

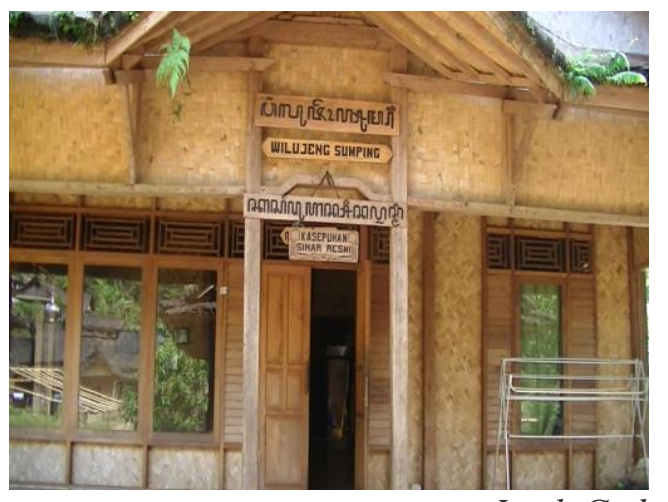

Imah Gede

Kasepuhan Sinar Resmi sejak tahun 2003 dipimpin oleh Abah Asep Nugraha. Beliau memiliki incu putu 'pengikut' di dalam dan di luar Desa Sirna Resmi. Kasepuhan Sinar Resmi berawaldari perpindahan Kampung Gede dari Lebak 
Selatan ke Sukabumi Selatan di Kampung Bojongsono oleh Ki Jasiun. Putra Jasiun, yaitu Abah Rusdi memindahkan Kampung Gede ke Kampung Cicemet, sukabumi Selatan. Putra Abah Rusdi , yaitu Abah Aryo memindahkan Kampung Gede sebanyak tiga kali, yaitu ke Kampung Waru, Cidadap dan terakhir ia memindahkan ke Cisarua. Setelah Abah Aryo meninggal, kasepuhan diwariskan pada Abah Ujat. Sesungguhnya, saat itu Abah Ujat menjabat sebagai kepala desa. Oleh karena itu, Abah Ujat memercayakan kasepuhan pada Abah Anom. Berdasarkan wangsit yang diterimanya, Abah Anom memindahkan kasepuhan ke Ciptarasa lalu berpindah kembali ke Ciptagelar. Melalui wangsit yang diterimanya kembali, Abah Anom membuka kasepuhan baru di Desa Sirna Resmi dengan kasepuhan bernama Kasepuhan Sinar Resmi, Cisolok, Sukabumi. Pada tahun 2003 Abah Ujat meninggal dan kepemimpinan dilimpahkan pada putranya, Abah Asep Nugraha, yang saat itu bertempat tinggal di Jakarta. Karena rasa tanggung jawab yang besar, Abah Asep menerima wangsit tersebut. Karena kata sirna yang berkonotasi negatif, yaitu artinya 'lenyap', Abah Asep Nugraha menggantinya dengan dengan sinar yang artinya 'bersinar' untuk nama depan kasepuhan sehingga kasepuhan berubah namanya menjadi Kasepuhan Sinar Resmi.

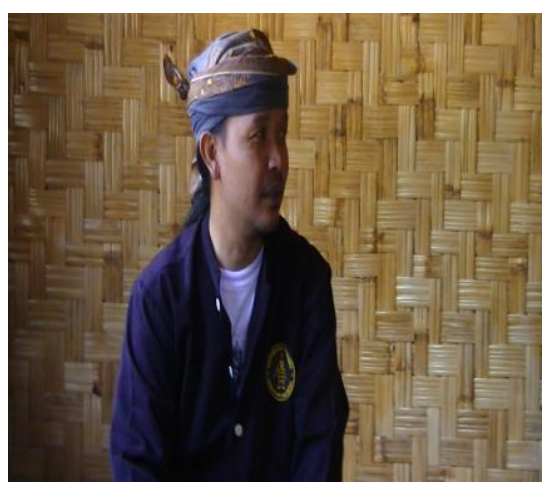

Abah Asep

2. Tradisi Lisan sebagai Indentitas Kasepuhan Sinar Resmi
Masyarakat Kasepuhan Sinar Resmi bermatapencaharian di sektor pertanian. Dengan kata lain, untuk memenuhi kebutuhan hidup, masyarakat kasepuhan sangat bergantung pada sumber daya alam yang berorientasi pada sistem pertanian tradisional dalam berbagai cara, yaitu ngahuma 'berladang', bersawah, dan berkebun. Sistem pertanian tradisional dilaksanakan sesuai dengan tradisi adat Banten Kidul, yaitu hanya panen satu kali dalam setahun, selebihnya lahan diistirahatkan. Masyarakat mempercayai bahwa tanah setelah ditanami perlu dipulihkan dan dikembalikan untuk mencapai keseimbangan dan keselarasan alam. Lahan pun tidak diperkenankan menggunakan bahan kimia selain yang tersedia di alam. Di samping itu, sisi filosofis masyarakat adat Sinar Resmi menyandarkan seluruh sendi-sendi kehidupan adat pada kalender siklus padi, misalnya masa tanam padi antara 4-9 bulan dimetaforkan sebagai seorang ibu yang hanya bisa melahirkan satu kali dalam setahun. Dengan panduan rasi bintang di langit, yakni saat rasi bintang kidang mulai condong ke Barat, penanaman padi dapat dimulai. Kearifan lokal ini mampu menghindari serangan hama padi karena pada saat bintang kidang mulai terbenam yang dalam istilah Sunda disebut dengan tilem kidang turun kungkang pada bulan Mei, hama padi mulai bermunculan sehingga tanaman harus sudah dipanen. Kearifan lokal lain yang berkaitan dengan penanaman padi yang mengangkat keunggulan petani di Kasepuhan Sinar Resmi adalah memandang bumi yang di dalamnnya mengandung lahan tanaman padi sebagai ibu dan langit adalah sebagai ayah.

Sementara itu, mantra-mantra yang dibacakan dalam tahapan ritual penanaman padi juga diyakini menjadi penentu keberhasilan panen. Berikut tahapantahapan ritual yang dilakukan masyarakat kasepuhan semasa penanaman padi.

(1) nyacar pihumaeun: ritual membuka ladang dengan terlebih 
dahulu membakar kemenyan dan memanjatkan doa;

(2) ngaseuk: menanam padi di huma dengan memasukkan benih ke dalam aseuk;

(3) beberes mager: ritual menjaga padi dari serangan hama.

(4) ngarawunan: ritual meminta agar padi tumbuh dengan subur dan sempurna.

(5) mipit: memanen padi pertama yang dilakukan oleh Abah Asep;

(6) ngadiukkeun pare di leuit: ritual menyimpan padi di lumbung;

(7) nutu: kegiatan menumbuk padi pertama hasil panen;

(8) ngabukti atau nganyaran: kegiatan ritual menanak nasi hasil panen pertama. Kegiatan ini dilaksanakan oleh Ambu (istri kepala adat); dilanjutkan dengan mencicipi nasi pertama hasil panen.

(9) tutup nyambut: kegiatan yang menandakan selesainya seluruh aktivitas pertanian yang ditandai dengan acara selamatan.

Puncak ritual ditutup dengan upacara seren taun 'serah taun' selama tiga hari tiga malam. Upacara seren taun merupakan sikap responsif masyarakat di sekitar Kasepuhan Sinar Resmi untuk mensyukuri hasil panen, serta sebagai bukti penghormatan terhadap warisan leluhur melalui pemertahanan adat, serta sebagai hiburan untuk masyarakat yang telah bekerja selama satu tahun masa pertanian. Dengan demikian, dalam konsep kosmos, padi menjadi pusat kehidupan masyarakat. Sebagai bentuk penghormatan tertinggi, padi dipersonifikasikan dengan seorang dewi, yaitu Nyi Pohaci Sanghyang Asri. Karena pasangan hidup manusia, menjadi kewajiban manusia merawat padi, sejak ia ditabur di sawah sampai dengan dipanen. Dengan filosofi ini, masyarakat kasepuhan pantang memperjualbelikan padi.

Rangkaian acara Seren Taun dimulai dengan musyawarah yang dalam istilah kasepuhan disebut dengan ponggokan musyawarah keluarga'. Ponggokan melibatkan seluruh incu putu untuk menentukan besar biaya yang diperlukan untuk prosesi adat Seren Taun. Berikutnya, pemimpin kasepuhan, Abah Asep Nugraha melakukan ziarah ke makam leluhurnya, mulai dari Abah Ujat, Abah Arjo, Uyut Rusdi, Uyut Jasiun, makam yang berada di Tegal Lumbu, makam di Pasir Talaga, makam di Lebak Binong, makam di Lebak Larang, dan makam leluhur di Cipatat, Bogor. Ziarah kubur ke para leluhur yang dilakukan oleh pemimpin adat, dapat ditafsirkan sebagai bakti penghormatan pada pemimpin pendahulu dan memperlihatkan pada generasi penerus kasepuhan tentang geneologis atau sistem kekerabatan yang ada di kasepuhan berdasarkan trah atau darah-turunan.

Prosesi adat yang berkaitan dengan padi tersebut menunjukkan bahwa masyarakat adat Kasepuhan Sinar Resmi adalah masyarakat yang bersandar pada budidaya padi. Pasca panen, masyarakat kasepuhan menyimpan padi di leuit 'lumbung'. Setiap petani wajib menyimpan satu pocong padi di leuit si jimat yang merupakan lumbung komunal. Lumbung-lumbung padi kasepuhan dan masyarakat adat dalam istilah Sumardjo (2011) disebut sebagai bank genetik. Di dalam bank genetik ini tersimpan berbagai varietas padi. Abah Asep Nugraha, pemimpin kasepuhan, menuturkan bahwa terdapat puluhan bahkan ratusan (140) varietas padi yang dikenal oleh masyarakat adat Sinar Resmi yang terawetkan dalam lumbung-lumbung yang berada di kasepuhan. Padi yang disimpan di lumbung tidak dipisahkan dari tangkainya, bergantung pada tali bambu (pocongan). Pocongan padi disimpan pada galah bambu dengan menggunakan batang kayu. Dengan cara ini padi tetap mengering dan memiliki kadar air yang tidak berubah. Pocongan padi disimpan dalam leuit yang berbentuk unik, berpintu satu, dan beratap rumbia. Rancangan ini mampu menahan bocor dan menutup jalan tikus. 


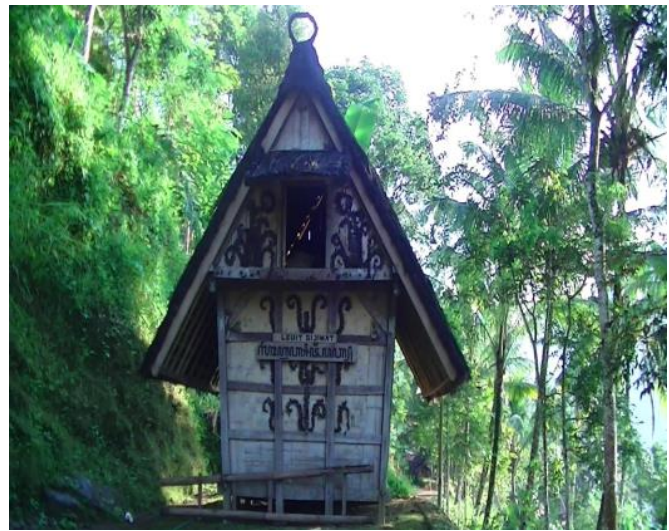

Leuit Si Jimat

Puncak acara Seren Taun ditandai dengan upacara Ngadiukkeun Pare atau memasukkan padi secara simbolik ke dalam leuit si jimat oleh pemimpin kasepuhan. Pembacaan doa atau mantra yang intinya mensyukuri atas restu alam semesta dan para leluhur yang telah menjaga masyarakat Kasepuhan Sinar Resmi. Leuit si jimat ini berfungsi sebagai bank yang diperuntukkan bagi masyarakat ketika mereka membutuhkan padi atau digunakan sebagai benih padi di ladang. Sejak 17 tahun terakhir, masyarakat Kasepuhan Sinar Resmi berhasil berswasembada padi. Ketika di tempat lain harga bahan pangan naik karena inflasi, masyarakat adat Kasepuhan Sinar Resmi stabil dengan kemandirian pangan yang dimilikinya.

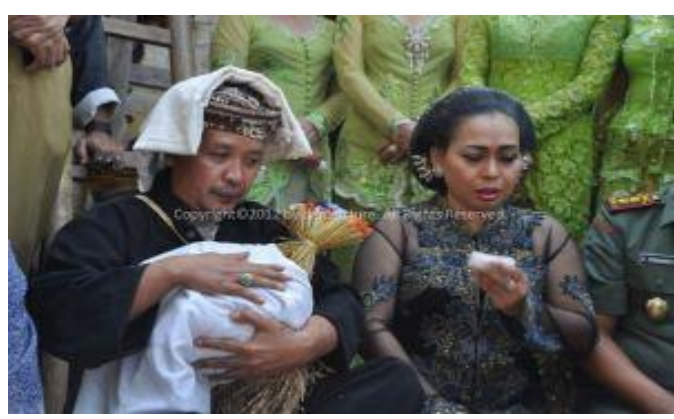

Ritual Ngadiukkeun Pare

Gondang Buhun dan Dogdog Lojor, seni pertunjukan yang menjadi ciri Kasepuhan Sinar Resmi mengiringi prosesi adat Seren Taun dengan lantunan lagu berbahasa Sunda kuno. Gondang Buhun adalah seni pertunjukan yang berkaitan dengan penumbukan padi. Seni tradisi ini digelar setelah panen, dilakukan oleh kaum ibu, menggunakan lesung dan alu. Pukulan alu ke dalam lesung dilakukan sedemikian rupa sehingga menghasilkan irama yang indah. Gondang Buhun yang digelar di Kasepuhan Sinaresmi, Cisolok, Sukabumi hanya dilakukan satu tahun sekali dalam rangka upacara Seren Taun. Permainan Gondang di luar acara Seren Taun biasa disebut dengan tutunggulan yang berarti nutu atau numbuk. Sesuatu yang ditumbuk berupa gabah kering sampai menjadi beras, atau dari beras menjadi tepung. Tradisi menumbuk inilah yang kemudian menjadi seni pertunjukan Gondang. Pertunjukan Gondang sekadar permainan nada dan irama yang poliponis, artinya kaum ibu atau remaja tidak benar-benar menumbuk padi, tetapi hanya menumbukkan alu ke dalam lesung.

Setelah acara menumbuk padi dilanjutkan dengan upacara Ngabukti. Upacara ini merupakan satu tahapan prosesi upacara adat Seren Taun untuk mensyukuri hasil panen selama satu tahun. Ngabukti atau disebut juga Nganyaran adalah ritual menanak nasi hasil panen pertama yang dilakukan oleh $A m b u$ 'permaisuri' kasepuhan yang khusus dipersembahkan pada Abah, pemimpin kasepuhan. Ritual ini sesungguhnya mengandung makna bukti kesetiaan seorang istri pada suami yang diwujudkan dalam bentuk persembahan makanan hasil olahan sendiri.

Selama prosesi adat itu berlangsung, seni Dog-dog Lojor, sejenis Angklung Buncis atau Angklung Buhun terus menemani Ambu dan para ibu, abdi kasepuhan, sejak mencuci beras sampai dengan menanak nasi. Dog-dog Lojor adalah seni pertunjukan yang secara tradisi digunakan untuk mengiringi kegiatan melak pare 'menanam padi', Ngabukti, ngadiukkeun pare 'mengangkut padi dari sawah ke lumbung'. Seni ini menggunakan dog-dog panjang yang terbuat dari bambu. 


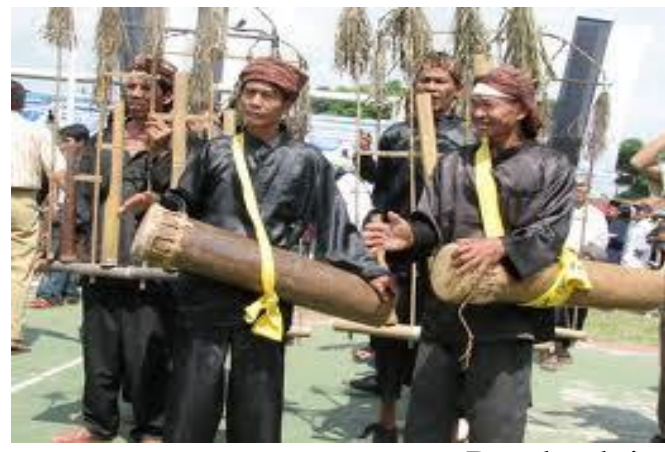

Dogdog lojor

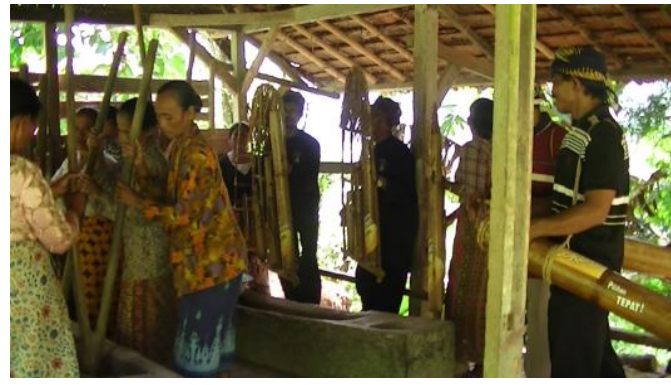

Gondang Buhun dan Dogdog Lojor

\section{Pengelolaan Hutan Lindung}

Sebagaimana dikemukakan bahwa pertanian huma dan sawah merupakan kegiatan pertanian yang mendominasi masyarakat kasepuhan karena dari huma dan sawah, masyarakat kasepuhan menanam padi sebagai komoditas pertanian utama. Sesungguhnya, disamping menanam padi, masyarakat kasepuhan juga memanfaatkan sumber daya alam yang ada untuk keperluan hidup, semisal menanam talun (kayu) dan menanam obat. Ketika pemerintah menetapkan salah satu kawasan di daerah Cisolok, Sukabumi sebagai wilayah konservasi yang disebut dengan Taman Nasional Gunung Salak (TNGHS) yang sampai saat ini dimanfaatkan oleh masyarakat adat kasepuhan terjadi perbedaan pandangan dalam mengelola hutan. TNGHS merupakan pegunungan hujan tropis alam terbesar yang tersisa di Jawa Barat dengan tiga jenis ekosistem utama, yaitu hutan hujan dataran rendah, hutan hujan dataran tinggi, dan hutan hujan pegunungan. Secara administratif taman nasional meliputi dua provinsi, Jawa Barat dan Banten serta tiga kabupaten: Bogor, Sukabumi, Lebak.
TNGHS dipandang mempersempit akses masyarakat kasepuhan dalam kegiatan pertanian. Namun, pihak TNGHS dapat memahami bahwa masyarakat adat Kasepuhan Sinar Resmi sebagai aset budaya bangsa yang lebih dahulu mendiami kawasan itu serta untuk memenuhi kebutuhan hidupnya bergantung pada sumber daya alam dengan memanfaatkan hutan. Penyelesaiannya, kedua belah pihak bersepakat mengelola sumber daya alam secara bersama-sama. Upaya kebersamaan ini berkaitan dengan peningkatan kesejahteraan masyarakat kasepuhan yang dikenal dengan MKK (Model Kampung Konservasi). Lembanasari dalam (Nisbah: 2011) menggambarkan bahwa kampung konservasi ini merupakan komunitas tertentu yang mampu hidup bersama alam dan di dalamnya dilakukan kegiatan pelindungan secara mandiri, mampu menjaga ekosistem, dan secara ekonomi bisa memberikan kesejahteraan bagi masyarakat atau berlangsungnya pemanfaatan sumber daya alam hayati di dalam kawasan konservasi secara berkelanjutan.

Di samping itu, MKK dilakukan untuk tujuan konservasi dan kesejahteraan masyarakat yang didasarkan melalui strategi penyelesaian konflik dan penguatan kelembagaan serta strategi pengembangan ekonomi masyarakat.

Beberapa kegiatan MKK yang dijalankan, antara lain, pengadaan bibit tanaman, seperti bibit aren dan tanaman kayu yang dapat dimanfaatkan oleh masyarakat untuk mendukung pertanian. Kemudian, pemberian dana usaha kegiatan ekonomi tambahan, seperti untuk peternakan dan masyarakat kasepuhan diberi keleluasaan mengolah lahan asalkan tidak memperluas lahan, tidak memiliki lahan, dan tidak menebang kayu.

Program MKK yang bertujuan membantu perekonomian masyarakat melalui alternatif usaha ekonomi di bidang lain, menurut pimpinan kasepuhan, Abah Asep Nugraha, dipandang kurang sesuai dengan situasi karena program ini hanya dijadikan semacam proyek agar 
masyarakat tidak bergantung pada hutan. Bah Asep mengklaim secara hukum adat bahwa sesungguhnya lahan-lahan tersebut masih menjadi hak kasepuhan dan bagi masyarakat kasepuhan, kami siap untuk mengolahnya.

\section{PENUTUP}

Uraian ringkas tentang kehidupan masyarakat adat Kasepuhan Sinar Resmi, Cisolok, Sukabumi yang mampu memenuhi kebutuhan kehidupan sehari-hari dari sumber daya alam dengan menjalankan tradisi leluhur dalam sektor pertanian merupakan salah satu upaya penguatan identitas bangsa. Tradisi lisan dalam sektor pertanian tersebut adalah ritual pemuliaan padi mulai mencangkul tanah, menebar bibit padi (tandur), menyiangi rumput, dan memanen padi sampai dengan ritual memasukkan padi ke dalam leuit si jimat dalam upacara Seren Taun (ketika orang mulai mengikat padi, menuju lumbung, dan menatanya di lumbung padi) dan memasak pertama beras baru dapat dipandang sebagai kearifan lokal sekaligus identitas budaya masyarakat Kasepuhan Sinar Resmi. Ritual pemuliaan dan penghormatan pada dewi padi, yaitu Dewi Sri yang diyakini memberi kesuburan tanaman padi menjadi cerminan masyarakat ladang atau masyarakat agraris. Pertunjukan seni yang diyakini sebagai tradisi lisan dalam ritual pemuliaan padi tersebut adalah Dogdog Lojor serta Gondang Buhun.

Di samping itu, masyarakat adat Kasepuhan Sinar Resmi yang hidup di lereng kawasan Gunung Halimun Salak secara perekonomian tidak mengalami perubahan setelah daerah itu menjadi kawasan konservasi Taman Nasional Halimun Gunung Salak. Untuk memenuhi kebutuhan hidupnya, masyarakat kasepuhan tetap mengelola dan memanfaatkan hutan tanpa harus merusak alam. Pengelolaan alam untuk menafkahi kebutuhan hidup tersebut berjalan secara harmonis dengan pranata sosial yang menjadi pegangan masyarakat adat yang sudah berlangsung secara berabad-abad dan tidak berubah dari generasi ke generasi.

Kasus yang terjadi di masyarakat adat Kasepuhan Sinar Resmi, Cisolok, Kabupaten Sukabumi ini minimal dapat menjadi model atau tawaran bagi siapapun dalam pembangunan penguatan identitas bangsa dan rasa nasionalisme melalui pengembangan budaya tradisi.

\section{DAFTAR SUMBER}

Baso, Ahmad. 2003.

Tradisi sebagai Invensi dalam Eseiesei Bentara 2003, Jakarta: Kompas.

Damono, Sapardi Djoko. 2011.

"Bunyi, Aksara, Gambar: Beberapa Catatan Awal" dalam Pujiastuti, Titik \& Tommy Christomy. Teks, Naskah, dan Kelisanan Nusantara. Depok: Yayasan Pernaskahan Nusantara.

Danandjaja, James. 2008.

"Pendekatan Folklore dalam Penelitian Bahan-Bahan Tradisi Lisan" dalam Pudentia (Editor). Metodologi Kajian Tradisi Lisan. Jakarta: Asosiasi Tradisi Lisan.

Dewi, Trisna Kumala Satya. 2011. "Dewi Sri sebagai Mitos Kesuburan dan Realitanya dalam Masyarakat Jawa" dalam Pujiastuti, Titik \& Tommy Christomy. Teks, Naskah, dan Kelisanan Nusantara. Depok: Yayasan Pernaskahan Nusantara.

Dienaptra, Reiza D. 2005.

"Sejarah Kertas di Indonesia" dalam Sabana dan Hawe Setiawan (Editor) Legenda Kertas. Bandung: Kiblat.

Ekadjati, Edi. 2005.

"Melestarikan Naskah Suda" dalam Sabana dan Hawe Setiawan (Editor) Legenda Kertas. Bandung: Kiblat.

Hapsarin, Cin. 
"Desain Budaya dalam Tradisi Lisan: Perjalanan Suara yang Hilang".

Ikram, Achadiati. 2008.

"Beraksara dalam Kelisanan" dalam Pudentia (Editor) Metodologi Kajian Tradisi Lisan. Jakarta: Asosiasi Tradisi Lisan.

KBBI. 1999.

Jakarta: Balai Pustaka.

humaniora.uin-malang.ac.id/index php?option=com_phocadownload\& view $=$ categori\&download $=33$ desain budaya-dalam tradisi lisan

Melayu online.com. 17 Oktober 2012. "Prof. Pudentia Maria Purenti Sri Sunarti (Pudentia MPSS)

Ong, Walter J. 1982.

Orality and Literacy: The Technologizing of the Word, London and New York: Methuen.

Pudentia (editor). 2008.
Metodologi Kajian Tradisi Lisan. Jakarta: Asosiasi Tradisi Lisan.

Pudentia. 2012.

"Pelindungan Tradisi Lisan Nusantara". Bandung: Balai Bahasa Provinsi Jawa Barat.

Pudentia. 2008.

"Ketika Peneliti Harus "Bercerita" tentang Tradisi Lisan. Dalam Pudentia (Editor) Metodologi Kajian Tradisi Lisan. Jakarta: Asosiasi Tradisi Lisan.

Sumardjo, Jakob. 2003.

Simbol-Simbol Artefak Budaya Sunda: Tafsir-Tafsir Pantun Sunda. Bandung: Kelir.

Vansina, Jan. 1985. Oral Tradition as History. Oxford: James Currey Publishers.

(Telah dipresentasikan dalam Seminar Internasional HISKI November 2012 di UNY, Yogyakarta) 